\title{
Intergroup Competition Mitigates Effects of Reward Structure on Preference-Consistency Bias and Group Decision Failure
}

\author{
Carsten K. W. De Dreu ${ }^{1,2}$ (D) Tim R. W. de Wilde ${ }^{3} \cdot$ Femke S. Ten Velden $^{4}$
}

Accepted: 10 April 2021 / Published online: 16 April 2021

(C) The Author(s) 2021

\begin{abstract}
Group discussion often becomes one-sided and confirmatory, with poor decisions as the unfortunate outcome. Here we examine whether intergroup competition amplifies or mitigates effects of individual versus team reward on information sharing biases and group decision quality. Individuals $(N=309)$ in 103 interacting groups were given private information on four decision alternatives and discussed a joint decision. Private information was distributed such that groups faced a "hidden profile" in which pushing for initial preferences and commonly held information prohibits the group from finding the best alternative. Group members were rewarded for team or individual performance, and groups faced intergroup competition or not. Whereas intergroup competition did not influence common-information bias, we find that when intergroup competition is absent, groups under individual (versus team) reward have stronger preference-consistency bias and make poorer decisions. When intergroup competition is present, however, groups under individual reward perform as good as groups under team reward. Results resonate with the possibility that intergroup competition overshadows within-group rivalry, and can promote even-handed discussions within small groups of decision-makers.
\end{abstract}

Keywords Intergroup competition · Group discussion · Communication bias · Team performance $\cdot$ Cooperation

Carsten K. W. De Dreu

c.k.w.de.dreu@fsw.leidenuniv.nl

1 Institute of Psychology, Leiden University, PO Box 9555, 2300 RB Leiden, The Netherlands

2 Center for Experimental Economics and Political Decision Making, University of Amsterdam, Amsterdam, The Netherlands

3 The Netherlands Institute for Social Research - SCP, Amsterdam, The Netherlands

4 Department of Psychology, University of Amsterdam, Amsterdam, The Netherlands 


\section{Introduction}

In both ancestral and contemporary societies, important decisions are often delegated to and made by small groups of people. One possible advantage of such practice is that groups bring together a broader and more diverse base of information and knowledge that can be used to achieve high quality decisions (Bahrami et al. 2010; Laughlin et al. 2006). This "two-heads-are-better-than-one" advantage is, unfortunately, easily off-set by two potent information sharing biases (De Dreu et al. 2008; Faber et al. 2017; Lu et al. 2012; Mesmer-Magnus and DeChurch 2009). First, group members disproportionally share "common" information known to all others and withhold "unique" information only known to themselves (Gigone and Hastie 1993; Stasser and Titus 1985; Stasser et al. 2000). Second, individuals disseminate information that is consistent rather than inconsistent with their personal preferences, interest, and opinions (Faulmüller et al. 2012; Greitemeyer and Schulz-Hardt 2003). Alone and in combination, the common-information and preference-consistency bias can make group discussions unbalanced, confirmatory, and polarized towards a consensually shared yet often sub-optimal decision (Brodbeck et al. 2007; De Dreu et al. 2008; Kerr et al. 1998). Indeed, the confluence of these information sharing biases has been identified as key to high-profile group decision failures, such as the Bay of Pigs invasion in Fidel Castro's Cuba in 1961 (Janis and Mann 1977), the Challenger Space Shuttle debacle in 1986 (Esser and Lindoerfer 1989), and the way the Carter Administration dealt with the Iranian-hostage crisis (Aldag and Fuller 1993; Tetlock et al. 1992).

Existing work on information sharing biases and group-decision failures remains limited to groups operating in isolation (De Dreu et al. 2008; Laughlin et al. 2006; Kerr and Tindale 2004). As high profile cases illustrate, however, group decision-making often takes place in the context of other groups with whom there is some form of competition for status and resources. In such cases, the group's decision-performance relative to its competitors can be as important as its objective quality for group survival and prosperity (Akinola et al. 2016; Bowles 2009; Burton-Chellew et al. 2010; Böhm and Rockenbach 2013; Nijstad and De Dreu 2012; Wittchen et al. 2011). To illustrate: When two research teams independently work on the same scientific problem it matters whether they "get it right" but also, or perhaps primarily, which team got it right first.

Recent advances in the study of within-group dynamics have shown that the presence of intergroup competition and conflict can boost within-group trust, increases the cooperative provision of group goods, and facilitates the coordination of collective action (De Dreu et al. 2016; Van Bunderen et al. 2018; Yang et al. 2020; for reviews see Balliet et al. 2014; De Dreu et al. 2020). What remains unknown, however, is whether and how intergroup competition influences withingroup information sharing biases and decision-making. In fact, there is reason to expect that intergroup competition has distinctly different consequences for the emergence of common-information bias and for preference-consistency bias. In general, the common-information bias is partly due to the fact that commonly 
held information is statistically more likely to be shared than uniquely held information (Schulz-Hardt and Mojzisch 2012), and partly due to the fact that sharing common information provides for more social validation than unique information (Bowman and Wittenbaum 2012; Mojzisch et al. 2008; Wittenbaum et al. 1999). Intergroup competition associates with increased within-group conformity (Henrich and Boyd 1998; Janis and Mann 1977; Bond and Smith 1996), increased self-censoring, and reduced tolerance for dissent (Janis and Mann 1977; Kruglanski et al. 2006). Because these processes fuel the common-information bias (Brodbeck et al. 2007; De Dreu et al. 2008), intergroup competition may result in stronger common-information bias within groups (Hypothesis 1a).

An opposite effect can be expected for the preference-consistency bias. The preference-consistency bias is partly rooted in the well-documented tendency for people to actively search for and recall information that supports and/or does not disconfirm their own preexisting beliefs and preferences (e.g., De Dreu and Van Knippenberg 2005; Hart et al. 2009; Faulmüller et al. 2010; Stangor and McMillan 1992). The sharing of preference-consistent information is, however, grounded in the desire to persuade others of one's own point of view (Dayeh and Morrison 2020; De Dreu et al. 2008) and in the desire to be understood by fellow group members. When, for example, participants saw that their discussion partner understood their views well, the preference-consistency bias was substantially reduced (Faulmüller et al. 2012). Because intergroup competition focuses individuals within groups on group rather than personal interests and preferences (Bowles 2009; Bernhard et al. 2006; Bornstein 2003; De Dreu and Gross 2019), intergroup competition may reduce commitment to personally preferred decision alternatives and the desire to persuade others of one's own perspective. If true, we should see that intergroup competition reduces the preference-consistency bias in information sharing (Hypothesis 1b).

We tested these hypotheses in an experiment with 103 freely interacting, threeperson groups tasked with choosing the best among four possible decision alternatives. Individuals within groups privately read case materials with items about each decision alternative that all other group members also received (common items) and items about each decision alternative no other group member was given (unique items). The common and unique items were structured and distributed in such a way that, prior to group deliberations, all group members preferred a sub-optimal decision alternative, and that when group deliberations would focus on preference-consistent and/or commonly held information, groups would reject the best alternative more often than when group deliberations were unbiased (Faulmüller et al. 2012; Kolb and Van Swol 2018; Stasser and Titus 1985; Stasser et al. 2000; De Wilde et al. 2017, 2018; Scholten et al. 2007).

In our experiment, half of the groups were rewarded for team performance and the other half were rewarded for individual performance (Chen et al. 2012). This variation in within-group reward structure allowed us to incentivize within-group dynamics to the same extent as between-group dynamics. In addition, team rewards induce a pro-social motivation and individual rewards fuel a more individualistic or competitive motivation (De Dreu et al. 2000; also see Dayeh and Morrison, 2020; De Dreu et al. 2008; Toma and Butera 2009). Relative to team rewards, individual rewards increase secrecy and distrust (Steinel et al. 2010), and reduce open-minded 
and cooperative dissemination of information (Chen et al. 2012; Dayeh and Morrison 2020; De Dreu 2007). This may manifest in stronger preference-consistency bias, and perhaps stronger common-information bias, under individual rather than team reward (Hypothesis 2) (Dayeh and Morrison 2020; Toma and Butera 2009; Toma et al. 2013; Wittenbaum et al. 2004). If true, we should expect effects of intergroup competition on preference-consistency bias (and perhaps common-information bias) to be particularly prominent in groups operating under individual rather than team reward (Hypothesis 3a). This means, ceteris paribus, that the presence (versus absence) of intergroup competition affects group decision quality especially when group are operating under individual rather than team reward (Hypothesis $3 b$ ).

\section{Method}

\subsection{Participants and Ethics}

The experiment was conducted between October 2015 and April 2016. We recruited 309 students $\left(M_{\text {age }}=22.31, S D=2.80\right.$ years; $\left.92 \mathrm{men}\right)$ to participate in a study on group decision-making for course-credit or $€ 10$. Although power analyses (using $\mathrm{G}^{*}$ Power) with effect size estimates of $W=1.32$ found in earlier work (Toma and Butera 2009) suggested eight groups per condition would be sufficient for $90 \%$ power, power analyses returned a sample size of $N=96$ to achieve $80 \%$ (at $p<0.05$ ) to be required for the detection of interaction effects at medium effect sizes. Accordingly, participants were assembled in 103 three-person groups and groups were randomly allocated to the conditions of a 2 (within-group reward: Individual versus Team $) \times 2$ (Intergroup competition: Absent vs. Present) design ( $\approx 25$ groups per condition).

There were no between-condition differences in sex composition $\left(\chi^{2}[3\right.$, $N=309]=0.91, p=0.824)$, mean age $(F[3,305]=1.62, p=0.184)$, or study major $(\chi 2[3, N=309]=3.62, p=0.305$; psychology [34\%], economics [7.1\%], 'other social science program' $[13.9 \%]$ or 'other' [45\%]). The study and experimental protocols and materials, including main hypotheses and analytic strategy was approved by the Ethics Review Board of the University of Amsterdam (2015/6-WOP-4692/7067); Participants provided written informed consent prior to participating and received full debriefing afterwards.

\subsection{Experimental Procedure}

Participants arrived in the lab in groups of three, were introduced to each other, and were placed in an individual room behind a personal computer which displayed instructions and recorded individual responses (De Wilde et al. 2017, 2018). Participants were explained the decision-making task, and were given 15 min to study the case materials (see "Decision Making Task"). When they had indicated which of the four decision options they preferred, the experimenter started a chat-program through which they could communicate by means of typed chatting; groups 
were given 20 min which earlier work has shown was more than enough for groups reach a joint decision (De Wilde et al. 2017). When the group reached a decision the experimenter closed the chat program and started up the next, individual, part of the experiment. Participants were asked to again indicate their individually preferred solution, responded to a short survey, and were thanked and paid for their participation. To preserve anonymity, payments based on performance were paid by bank-transfer.

\subsection{Decision-Making Task}

We used a hidden-profile decision-making task, developed for the current study and structured after tasks used in our previous work (De Wilde et al. 2018; Scholten et al. 2007). The group's task was to select the best candidate, out of four, for a job as a pilot for a large airline company. All participants received a folder with, for each job candidate, a short assessment report, a summarized job interview, a medical screening, and several hand-written notes ostensibly made by the interviewer during an interview session with the candidate. For each of the four candidates A, B, $\mathrm{C}$, and $\mathrm{D}$, the complete set of information contained a total of 10 relevant items that were either positive or negative. Participants were told that candidates were equivalent on several not-mentioned minimum requirements such as flight experience and educational background, and that group members would receive different information about the same candidates. Importantly, and unknown to participants, the information about the candidates was distributed among group members following the principles of a so-called hidden-profile (Stasser and Titus 1985; Stasser et al. 2000): Some items were given to all group members (shared items); other items were only available to one group member (unique items) (see Fig. 1A). The set of shared items was set up such that it would lead to a preference for one of the three suboptimal candidates (Candidate A, B, or D). However, when all unique items would be pooled and processed at the level of the group, Candidate $\mathrm{C}$ would emerge as the optimal choice. Thus, to be successful, participants within a group needed to exchange unique items and use them to update their decision preferences.

With two pilot studies with participants drawn from the same research population as the main experiment we ensured our distribution of information worked as intended. As a first test of our materials ( $N=83$ individuals) we investigated which candidate participants would pick based on their individual information. Only 11 participants (13\%) indicated $\mathrm{C}$ to be the correct candidate, which is below the expected percentage if all candidates were chosen equally often $(25 \%, p=0.007)$. In a second pilot study, 21 new participants received all three case files. Thus, participants read the common information three times, while needing to integrate the unique items from each of the candidates' information. Nineteen (90.5\%) participants picked candidate $\mathrm{C}$ as the correct candidate, which is higher than expected if all candidates were equally likely to be chosen $(25 \%, p<0.001)$. These two pilot studies thus confirm that only when all unique items are known individuals can achieve the optimal decision. Participants in these pilot studies did not participate in the main experiment. 


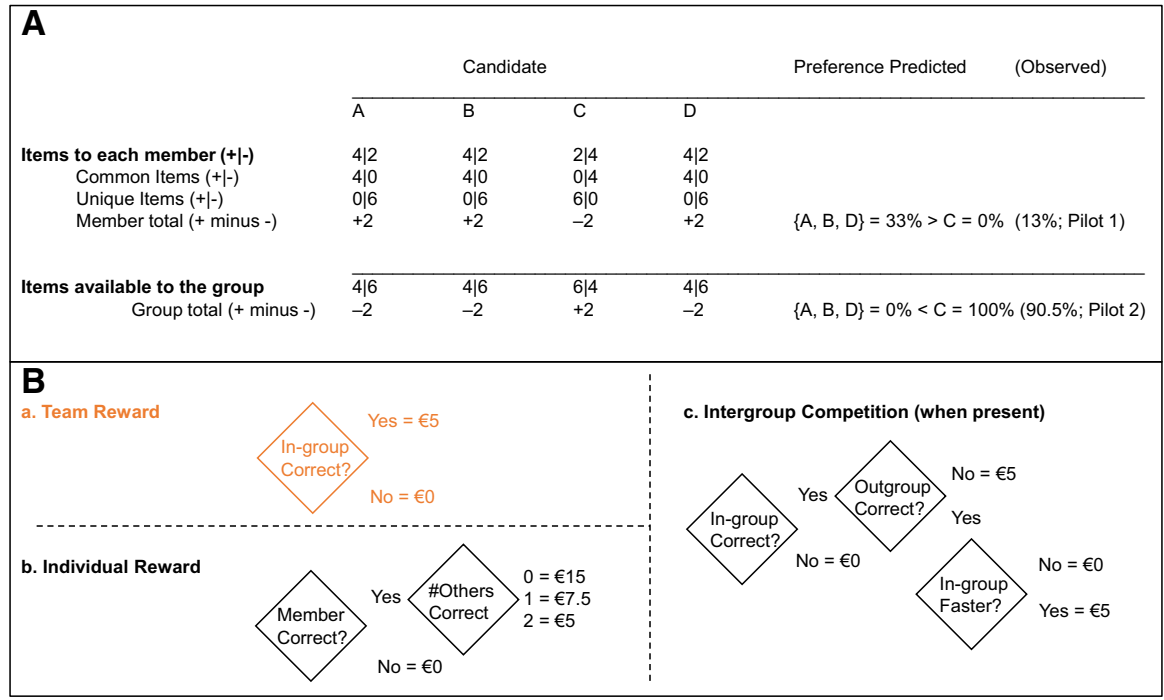

Fig. 1 Group decision-making task and reward manipulations. (A) Distribution of information between group members. At the individual level, group members received 2 negative and 4 positive items about candidate A, B and D (the positive items being commonly shared), and 4 negative and 2 positive items about candidate $\mathrm{C}$ (the negative items being commonly shared). This makes candidate $\mathrm{C}$ the least preferred choice option, which was confirmed in Pilot Experiment 1. In contrast, at the group-level, there were 4 positive (+) and 6 negative (-) items for candidate $\mathrm{A}, \mathrm{B}$ and $\mathrm{D}$, and 6 positive and 4 negative items for candidate $\mathrm{C}$, making $\mathrm{C}$ the optimal choice, which was confirmed in Pilot Experiment 2. (B) Rewards per group member depending on condition: (a) team-reward condition. (b) individual reward condition. (c) intergroup competition. All rewards are per group member. The total reward per individual is (a) or (b) + (c) ([c] is set at $50 \%$ probability in the intergroup absent condition)

\subsection{Within-Group Reward Structure and Between-group Competition}

Group members were instructed that following the group discussion they would first privately indicate their decision and then as a group they would also indicate their joint decision. When their group's decision was correct, their group would be rewarded $15 €$. In the team-reward condition, this bonus would be equally divided among all three members (thus regardless of the personal choice also submitted). In the individual-reward condition, the bonus would be divided among those group members whose personal choice was correct. Thus, if they were the only one with the correct solution within their group, they would earn $€ 15$; if two (three) members selected the correct candidate, each would receive $€ 7,50$ (€5) (also see Fig. 1B panels a and b) (Bowman and Wittenbaum 2012; Chen et al. 2012; De Wilde et al. 2018). Thus, group members' interests were more strongly aligned in the team-reward condition, than in the individual-reward condition (Dayeh and Morrison 2020).

Orthogonal to the within-group reward structure, we created (or not) betweengroup competition. In the intergroup competition condition, participants were told that their group would be paired with another group, and that the group that 
picked the correct candidate would win $€ 15$, to be equally distributed among the members of the winning group. If both groups were correct, the fastest group would win; if neither group was correct, no group would earn the bonus (Fig. 1B, panel c) (Chen et al. 2012).

We checked the manipulation of within-group reward structure in a post-task survey, in which participants individually rated their agreement with six statements ( 1 = completely disagree, 7 = completely agree): (1) 'While I was performing the decision-making task I tried to perform better than the other group members', (2) 'My own performance was more important than the performance of the group' and (3) 'I saw my group members as rivals', (4) 'While I was performing the decisionmaking task I tried to make sure that my group would find the correct candidate', (5) 'The performance of the group was more important than my individual performance' and (6) 'I saw my group members as partners'. Ratings (reverse coded for items 4-6) were intercorrelated (Cronbach's $\alpha=0.748$ ) and averaged in a single measure of competitive mindset. A mixed-model analysis, with a random intercept to account for group membership, indicated that group members operating under individual reward reported a more competitive mindset $(M \pm \mathrm{SD}=2.99 \pm 1.19)$ than group members under team-reward $(M \pm \mathrm{SD}=2.45 \pm 0.83)(F[1,99]=16.36$, $p<0.001, \eta_{\mathrm{p}}{ }^{2}=0.142$ ). In addition, we found a main effect for intergroup competition, showing that individuals had a more competitive mindset when intergroup competition was absent $(M=2.89, S D=1.11)$ rather than present $(M=2.54$, $S D=0.98)\left(F[1,99]=6.68, p=0.011, \eta_{\mathrm{p}}{ }^{2}=0.063\right)$. Within-group reward structure and between-group competition did not interact $(F[1,99]=0.68, p=0.410)$.

In the intergroup competition conditions, we assessed the impact of intergroup competition with two additional questions asked post-task ('I wanted my group to perform better than the other group' and 'I wanted to win from the other group;' both $1=$ completely disagree, $7=$ completely agree) (Spearman-Brown $r=0.725$ ). Analyses revealed that the experience of intergroup competition was similar in the individual-reward and the team-reward groups $(F[1,51]=0.66, p=0.422)$. In both types, average ratings exceeded the mid-point of the scale $(M=5.14, S D=1.11$, and $M=4.97, S D=1.19 ; t(77)=12.97, p<0.001, d=1.48$, and $t(80)=11.13, p<0.001$, $d=1.24)$.

\subsection{Behavioral Measures}

In addition to pre-discussion and post-discussion individual preferences (coded as correct [Candidate C] or incorrect [Candidate A, B, or D]), we assessed for each group whether their decision was correct $(1=$ yes; $0=$ no $)$. From the online group discussion transcripts we coded 4 variables, that were all easily countable and recognizable as we only coded preference statements when there could not have been any other interpretation. Therefore, it sufficed that one coder-unaware of the experimental conditions-did the coding work. A second coder reviewed the coding/counting and was in perfect agreement. In short, we counted how often each of the 40 pieces of relevant items were mentioned (repetitions included), and grouped these counts into (i) information exchange (total number of items mentioned; see Lu 
et al. 2012); (ii) preference statements (total number of times group members mentioned a preference; e.g., "I think candidate A is the best option"); (iii) unique items exchanged in proportion to the total number of items exchanged; and (iv) preference inconsistent items exchanged in proportion to the total number of items exchanged. Preference inconsistent items were those items that did not support the candidate a group member preferred prior to the group discussion (e.g., when a member selected candidate $\mathrm{A}$ prior to the group discussion, negative items about $\mathrm{A}$ and positive items about B, C, or D were coded preference inconsistent).

We constructed an index for both preference-consistency bias (the proportion of preference-consistent relative to inconsistent items; overall $M \pm S E=0.510 \pm 0.013$ ), and for common-information bias (the proportion of unique information relative to common information; overall $M \pm S E=0.475 \pm 0.0136$ ). At the level of the entire sample, the preference-consistency and common-information bias were not correlated, $r(103)=0.027, p=0.785$. Table 1 gives a breakdown of the information sharing means per experimental condition. We found no effects for preference consistent items (overall $M \pm S E=8.851 \pm 1.01$ ), or for the exchange of commonly held information (overall $M \pm S E=7.757 \pm 1.031$ ) (all $F \mathrm{~s}<3.000, p s>0.100$ ). For preference inconsistent items we found that groups had more preference-inconsistent items when operating under team rather than individual reward $(F[1,99]=5.637$, $\left.p=0.019, \eta_{\mathrm{p}}{ }^{2}=0.054\right)$. Effects for intergroup competition and the intergroup competition $\mathrm{x}$ reward structure were not significant $(F[1,99]=3.160, p=0.079$, $\eta_{\mathrm{p}}{ }^{2}=0.031$, and $\left.F[1,99]=3.403, p=0.068, \eta_{\mathrm{p}}{ }^{2}=0.033\right)$. For the exchange of unique information we found that groups exchanged more unique information when intergroup competition was absent rather than present $(F[1,99]=4.017, p=0.048$,

Table 1 Descriptive statistics for information sharing broken down by experimental condition

\begin{tabular}{|c|c|c|c|c|}
\hline \multirow[t]{3}{*}{ Within-Group Reward } & \multicolumn{4}{|c|}{ Intergroup Competition } \\
\hline & \multicolumn{2}{|l|}{ Absent } & \multicolumn{2}{|l|}{ Present } \\
\hline & Individual & Team & Individual & Team \\
\hline Common Information & $\begin{array}{l}6.893 \\
(1.042)\end{array}$ & $\begin{array}{l}9.493 \\
(1.041)\end{array}$ & $\begin{array}{l}6.840 \\
(1.003)\end{array}$ & $\begin{array}{l}7.872 \\
(1.022)\end{array}$ \\
\hline Unique Information & $\begin{array}{l}7.253 \\
(0.907)\end{array}$ & $\begin{array}{l}10.240 \\
(0.907)\end{array}$ & $\begin{array}{l}6.679 \\
(0.873)\end{array}$ & $\begin{array}{l}7.231 \\
(0.889)\end{array}$ \\
\hline Preference Consistent & $\begin{array}{l}8.573 \\
(1.027)\end{array}$ & $\begin{array}{l}10.280 \\
(1.028)\end{array}$ & $\begin{array}{l}7.765 \\
(0.989)\end{array}$ & $\begin{array}{l}8.872 \\
(1.010)\end{array}$ \\
\hline Preference Inconsistent & $\begin{array}{l}5.693 \\
(0.902)\end{array}$ & $\begin{array}{l}9.453 \\
(0.902)\end{array}$ & $\begin{array}{l}5.753 \\
(0.869)\end{array}$ & $\begin{array}{l}6.231 \\
(0.885)\end{array}$ \\
\hline Total Information & $\begin{array}{l}42.440 \\
(5.607)\end{array}$ & $\begin{array}{l}59.200 \\
(5.610)\end{array}$ & $\begin{array}{l}40.556 \\
(5.395)\end{array}$ & $\begin{array}{l}45.308 \\
(5.498)\end{array}$ \\
\hline Speaking Turns & $\begin{array}{l}160.96 \\
(11.294)\end{array}$ & $\begin{array}{l}177.24 \\
(11.291)\end{array}$ & $\begin{array}{l}101.60 \\
(10.868)\end{array}$ & $\begin{array}{l}95.08 \\
(11.075)\end{array}$ \\
\hline Word Count & $\begin{array}{l}1760.36 \\
(134.4)\end{array}$ & $\begin{array}{l}1950.08 \\
(134.5)\end{array}$ & $\begin{array}{l}1227.33 \\
(129.4)\end{array}$ & $\begin{array}{l}1130.57 \\
(131.9)\end{array}$ \\
\hline
\end{tabular}

Entries for each measure are Means (Standard Error) 
$\left.\eta_{\mathrm{p}}{ }^{2}=0.039\right)$ and when groups were under team rather than individual reward $(F[1$, $\left.99]=3.917, p=0.051, \eta_{\mathrm{p}}{ }^{2}=0.038\right)$. The intergroup competition $\mathrm{x}$ reward effect was not significant $\left(F[1,99]=1.855, p=0.176, \eta_{\mathrm{p}}{ }^{2}=0.018\right)$.

Bias in information exchange may be the result of differences in general communication differences, and to examine this we coded for each group discussion the number of speaking turns, and the total word count (see Table 1). Speaking turns and word count was strongly correlated, $r=0.907, p=0.0001(d f=103)$. The number of speaking turns was higher when intergroup competition was absent rather than present $\left(F[1,99]=40.376, p \leq 0.001, \eta_{\mathrm{p}}{ }^{2}=0.063\right)$. Correcting information sharing indices for speaking turns (or word count) did not, however, change the results or conclusions.

\subsection{Data Preparation and Analytic Strategy}

Only the materials and measures reported here were subjected to analyses and data were only pre-processed and analyzed after all data had been collected. No (groups of) participants were excluded; Unless otherwise noted, we used two-tailed tests with $p \leq 0.05$ as our criterion for statistical significance and interpreted $p \leq 0.10$ as indicating a trend. All analyses that included a group-level dependent variable (e.g., group decision quality) were analyzed at the group level. When analyses included only individual-level constructs (e.g., competitive mindset) we used Mixed-Model analyses in which we included a random intercept to account for group membership. In these analyses the degrees of freedom were adjusted by the extent to which group membership accounts for variation on the target measure. For instance, when the group membership intercept is redundant, analyses mirror an individual level test, while when group membership becomes more important the analyses will increasingly resemble the group level test. For the sake of consistency all information sharing variables were analyzed at the group-level as they were intended to be added to mediation-models explaining group decision quality (a group-level variable).

\section{Results}

Before group discussions, participants indicated their preferred alternative. Preferences were distributed in the same way among groups in all conditions $(0,1,2$ or 3 correct, $F[3,99]=0.99, p=0.400]$, in $68 \%$ of the groups a majority favored the same sub-optimal decision option (with no effect for treatment, $\chi^{2}[3, N=103]=1.732$, $p=0.630$ ) and no a priori differences between groups existed in their preference for the best alternative $\left(\chi^{2}[3, N=309]=2.910, p=0.405\right)$. In no single group did all members prefer the best alternative before discussion took place, and in only three groups a majority preferred the best alternative (one group in the individual reward/ intergroup competition absent condition, and two in the team reward/intergroup competition condition). Controlling for pre-discussion preferences in the analyses reported below never changed results and conclusions. 


\subsection{Group Decisions}

Group members discussed their joint decision and could talk about whatever they wanted before submitting their decision. Group decisions were coded as correct (Candidate $\mathrm{C}$ ) or incorrect $(\mathrm{A}, \mathrm{B}$, or $\mathrm{D})$ and analyzed using logistic regression. As anticipated, individual (versus team) reward reduced decision quality, $b \pm s e=1.07 \pm 0.43, z=2.51, p=0.012$. Whereas intergroup competition (versus absent) did not affect decision quality, $b \pm s e=-0.61 \pm 0.42, z=-1.44, p=0.149$, we did observe the expected reward $\mathrm{x}$ intergroup competition interaction (directional test: $b \pm s e=-1.70 \pm 0.92, z=-1.85, p=0.032$ ) (Fig. 2A). Consistent with Hypothesis $3 \mathrm{~b}$, we found that in the absence of intergroup competition, individual-reward groups $(12 \%$ correct) were outperformed by team-reward groups (52\% correct), $b \pm s e=-2.07 \pm 0.73, z=-2.82, p=0.002$, odds-ratio $=7.94$. Present intergroup competition, however, individual-reward (41\%) and team-reward (50\%) groups performed equally well, $b \pm s e=-0.37 \pm 0.55, z=-0.68, p=0.499$, odds-ratio $=1.45$. Thus, the presence of intergroup competition reduced the detrimental effect of individual (versus team) reward on group decision-making.

A similar conclusion follows from analyzing personal post-decision preferences (which was relevant for payment in the individual reward conditions). Intergroup competition (versus absent) did not affect post-discussion preferences, $b \pm s e=-0.108 \pm 0.251$, Wald $=1.85, p=0.667$, and individual (versus team) reward reduced the number of correct post-decision preferences, $b \pm s e=-0.950 \pm 0.254$, Wald $=13.971, p=0.001$. We also observed the expected reward $\mathrm{x}$ intergroup
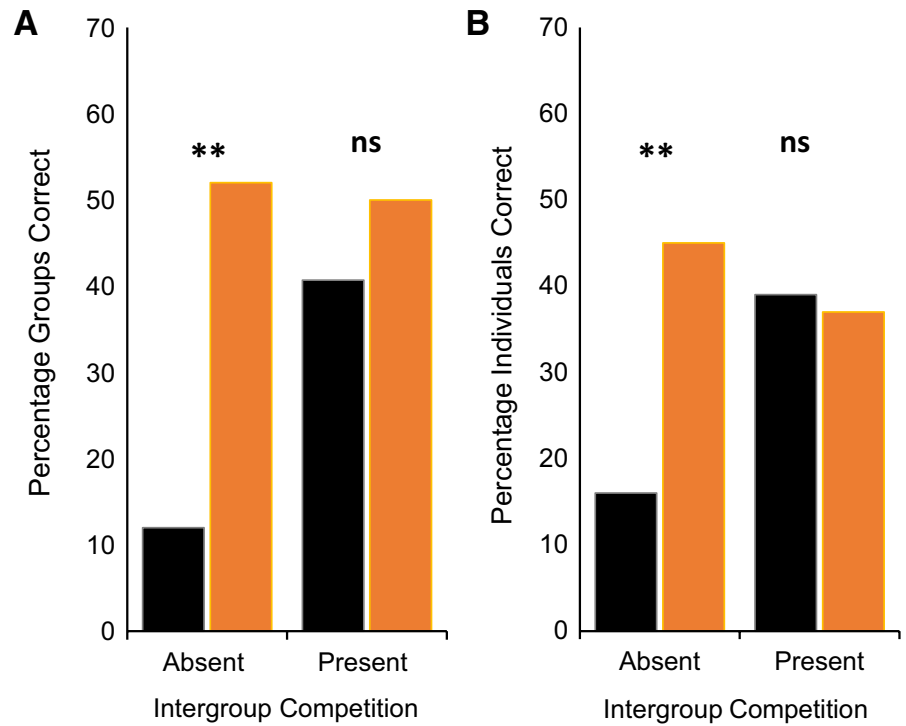

Fig. 2 Group decisions and personal preferences. (A) Percentage of groups making the correct decision (Candidate $\mathrm{C}$ ) as a function of individual (black) versus team (orange) reward and absence versus presence of intergroup competition. (B) Percentage of individuals indicating the correct decision as their personal preference as a function of reward and intergroup competition. $* * p<.025$, ns $=$ not significant 
competition interaction (directional test: $b \pm s e=-0.955 \pm 0.519$, Wald $=3.380$, $p=0.033$; controlling for pre-discussion preferences: $b \pm s e=-1.126 \pm 0.547$, Wald $=4.244, p=0.02$ ). When intergroup competition was absent, $16 \%$ (versus $45 \%$ ) of the individuals under individual (versus team) reward preferred the correct candidate $\mathrm{C}$; When intergroup competition was present, the difference between team reward (39\%) and individual reward (37\%) disappeared (Fig. 2B).

\subsection{Information Sharing}

From the group discussions we computed an index for both preference-consistency bias and for common-information bias (see Sect. 2). The preference-consistency bias negatively predicted the quality of group decisions $\left(r_{b}=-0.404, p=0.001\right.$, with $d f=103)$. Analysis of Variance with intergroup competition and reward structure as between-groups factors returned main effects for reward structure, $F(1$, 99 ) $=8.694, p=0.004, \eta_{\mathrm{p}}{ }^{2}=0.081$ (confirming hypothesis $1 \mathrm{~b}$ ) but not for intergroup competition, $F(1,99)=0.096, p=0.758, \eta_{\mathrm{p}}{ }^{2}=0.001$. The intergroup competition $\mathrm{x}$ reward structure was significant, $F(1,99)=5.275, p=0.024, \eta_{\mathrm{p}}{ }^{2}=0.051$. Consistent with Hypothesis 2 and 3a, we found that stronger preference-consistency bias in groups under individual rather than team reward when intergroup competition was absent $(F[1,99]=13.490, p<0.001)$ rather than present $(F[1,99]<1)($ Fig. 3AB $)$. The common information bias was also negatively related to the quality of group decisions $\left(r_{b}=-0.165, p=0.042\right.$, with $\left.d f=103\right)$ (per hypothesis 1a) but was not influenced by reward, intergroup competition, or their interaction (all $F[1,99]<1$ ) (Fig. 3CD).

We concluded with mediation analyses, predicting the effects of reward and intergroup competition, and their interaction, on decision quality through the preferenceconsistency bias. We focused on the proportion of preference-inconsistent information (Fig. 3B), as results thus far suggested that the sharing of unique information was not conditioned by reward or intergroup competition (Fig. 3D). We first examined the relationship between the preference-consistency bias and group decision quality as a function of reward and intergroup competition. Analyses showed that when intergroup competition was absent, the correlation between preference consistency-bias and group decision quality was negative and significant under team reward $(T=-0.416, p=0.014$, with $N=25)$ but not under individual reward $(T=-0.100$, $p=0.558$ with $N=25$ ) (Fig. 4A). When intergroup competition was present, the negative correlation between the preference consistency-bias and group decision quality was at trend-level under both team reward, $(T=-0.274, p=0.093$, with $N=27)$ and individual reward $(T=-0.286, p=0.086$, with $N=26)$ (Fig. 4B).

When computing a formal moderated mediation model (Process Model 8; Hayes 2013) we find Path (a) $t(99)=-2.30, p=0.024$; Path (b) $Z=3.25, p=0.001$; Path (c') $Z=-1.00, p=0.316$ (Fig. 4C). Thus, the proportion of preference-consistent relative to inconsistent items explained (i) the effect of within-group reward structure $\left(\mathrm{CI}_{95 \%}\right.$ : -2.54 to $-0.11 ; b_{\text {indirect-effect }} \pm \mathrm{se}=-1.05 \pm 0.63 ; 10,000$ samples), and (ii) moderation by intergroup competition: Absent: $b_{\text {indirect-effect }} \pm \mathrm{se}=1.19 \pm 0.57, \mathrm{CI}_{95 \%}: 0.34,2.48$; Present, $b_{\text {indirect-effect }} \pm \mathrm{se}=0.15 \pm 0.30, \mathrm{CI}_{95 \%}:-0.42,0.77$. 
A



C

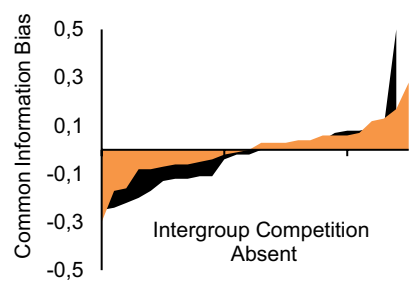

B Individual $\quad$ Team

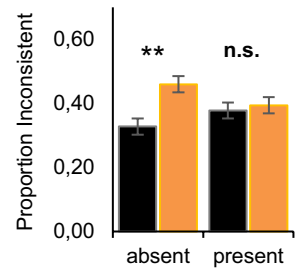

D

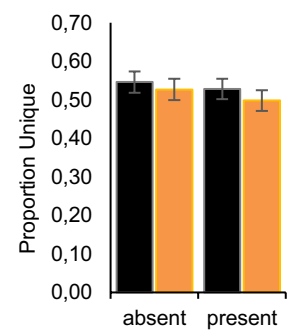

Fig. 3 Information sharing bias as a function of reward (team versus individual) and intergroup competition (absent versus present). (A) Preference-consistency bias for individual (black) and team (orange) reward for each group, rank-ordered from lowest to highest $(N=25$ and 26, respectively). Values below (above) zero indicate a preference inconsistency (consistency) bias. (B) Proportion of preference inconsistent items as a function of reward and intergroup competition ( $\operatorname{shown} M \pm 1 \mathrm{SE}$; ** $p<.01$, ns $=$ not significant). (C). Common-information bias for individual (black) and team (orange) reward for each group, rank-ordered from lowest to highest $(N=25$ and 27 , respectively). Values below (above) zero indicate a preference-inconsistency (consistency) bias. (D) Proportion of unique information items as a function of reward and intergroup competition (shown $M \pm 1 \mathrm{SE}$ )

\section{Conclusions and Discussion}

Intergroup competition reduced preference-consistency bias in information sharing, and increased the quality of group decisions. This set of findings emerged when individuals within groups performed for individual rewards and not when individuals within groups performed for team rewards. Intergroup competition can overshadow within-group rivalry and enhance within-group cooperation in public good provision games (Bowles 2009; Bernhard et al. 2006; Bornstein 2003; De Dreu and Gross 2019). Current findings are consistent with this perspective, suggesting that information sharing bias has its roots in within-group rivalry for personal rewards. The presence of intergroup competition, like working for a team reward, not only reduces within-group rivalry but also, as shown here, preference-consistency bias. This promotes in-group efficiency as well as the quality of decision-making in information-rich, complex environments.

At the outset, we anticipated two possible scenarios. The first possibility, confirmed by our data, was that intergroup competition (relative to its absence) reduces preference-consistency bias and therefore can promote the quality of group 


\section{A Individual Reward}


C

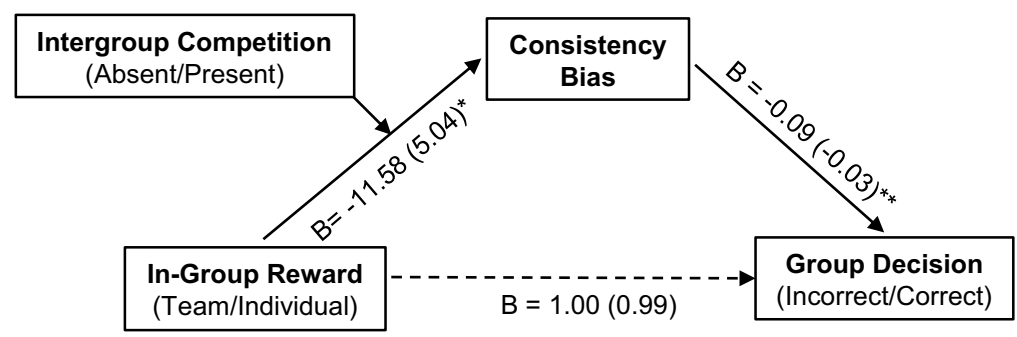

Fig. 4 Relationship between preference-consistency bias and group decision quality. (A) Individual reward groups when intergroup competition is absent (left panel; $N=25$ ) and present (right panel; $N=25$ ), rank-ordered for preference-consistency bias from lowest to highest. Solid (open) bars are groups making the incorrect (correct) decision. (B) Team reward groups when intergroup competition is absent (left panel; $N=27$ ) and present (right panel; $N=26$ ), rank-ordered for preference-consistency bias from lowest to highest. Solid (open) bars are groups making the incorrect (correct) decision. (C) Intergroup competition moderates the relationship between reward structure, preference inconsistent information, and group decision quality. Estimates are based on bootstrapping procedure with 10,000 bootstrap samples. ${ }^{*} p<0.05, * * p<0.01,{ }^{\text {ns }}$ not significant. Used Process Model 8 [Hayes, 2013]

decisions. The second possibility was grounded in work showing that intergroup competition can increase within-group conformity and intolerance for dissent, which may amplify the common-information bias that detract from high quality decision-making. We found no support for this alternative: Intergroup competition increased the quality of decision making in individual reward groups, rather than 
that it decreased quality in team reward groups. Also, intergroup competition had no effect on the common-information bias. Perhaps that within-group conformity and intolerance for dissent emerge especially when groups anticipate survival threat and swift and unified collective action is needed, and less when groups work towards opportunities for additional rewards (as in the current case; also see De Dreu and Gross 2019). Future research could disentangle the specific structure of intergroup competition to further understand when and why intergroup competition promotes or, instead, hampers even-handed discussions and decision-making.

Intergroup competition in the current experiment influenced the preference-consistency bias and did not influence the common-information bias. Whereas earlier studies observed these two biases to often co-occur, they also have distinctly different origins. For example, the desire to persuade others of own's own perspective (Toma and Butera 2009), and to be understood by one's interaction partner (Faulmüller et al. 2012) underlie the preference-consistency bias but not necessarily the common-information bias. Here we observed that intergroup competition and within-group reward structure interactively predicted the sharing of preferenceinconsistent information but not the sharing of preference-consistent information (see Sect. 2, and Table 1). This fits the idea that intergroup competition shifts people from being focused on personal goals towards a focus on group goals and induced "parochial cooperation" aimed at making the in-group stronger and able to out-perform rivaling out-groups (De Dreu et al. 2020).

One possible concern is that the presence of intergroup competition may have induced a sense of time pressure among group members (i.e., they were not only incentivized for deciding for the best alternative, but also to be the first within their pair to submit their decision). However, when we asked participants post-task whether they experienced time pressure during the decision making $(1=$ not at all, to $5=$ very much), we find a moderate level $(M \pm \mathrm{SE}=2.976 \pm 0.171)$ that does not deviate from the scale mid-point $(t<1)$ and is not conditioned by reward, intergroup competition, or their interaction (all $F[1,99]<1$ ). Second, others have shown that time pressure typically increases the prevalence of information sharing biases during group discussions and reduces the quality of group decision-making (Bowman and Wittenbaum 2012; Kelly and Loving 2004). If time pressure operated more when intergroup competition was present rather than absent, we should have seen increased information sharing bias and reduced quality of group decisions. On both variables, however, we found the opposite effect of intergroup competition.

Conclusions need to be taken in light of three study limitations. First, groups were confronted with a recruitment decision problem and needed to select the best candidate out of four possibilities. The intergroup competition was decided on the basis of which group got the "correct" solution (first). This set-up reflects situations we see among research and development teams, where the issue not only is to "get it right" but also to "get it right first," elements that we also see among organizational teams involved in developing sales campaigns, the production of news, and technological innovation (Nijstad and De Dreu 2012). Future research could invest in studying situations in intergroup competition takes different forms-instead of the current "all-or-nothing," intergroup competition can also create a rank-ordering within, for example, the over-arching organization 
with some teams earning a larger performance bonus or more symbolic praise than others. When the consequences of losing the competition may be less severe, the impact of intergroup competition on group deliberation and decision-making may be likewise less strong than we observed presently.

Second, our experimental task was admittedly more information-rich and complex than related work on intra- and intergroup dynamics using social dilemma (e.g., Van Dijk and De Dreu 2021) and intergroup contest games (e.g., De Dreu et al. 2020). At the same time, the group decision-making task had a solvable element to it and involved analytical work rather than finding common ground on some ideological or value-laden position (Bonner et al. 2016). Fact-based preferences may be easier to renounce than value-based positions (Harinck et al. 2000; Zhao et al. 2020). Future research could investigate current hypotheses in situations where group decision-making not only involved factual solutions but also finding consensus on political values and ideological positions.

Third and finally, groups in our experiments were self-managed and lacked a designated leader. Others have shown that the quality of group decision-making is conditioned by leadership (Nevicka et al. 2011; Van Ginkel and Van Knippenberg 2012) and that groups benefit from leadership when competing against other groups (De Dreu et al. 2016; Lopez 2020). Whether and how leadership mitigates information sharing bias and group decision failures when groups compete against outside rivals is yet unknown and herein lies another important question for future research.

Intergroup competition can be wasteful-the time and energy individuals invest in competing cannot be invested in wealth production (De Dreu and Gross 2019). When it comes to decision-making, we found no evidence for such a destructive effect of intergroup competition. The pattern of findings here is, in contrast, conducive to the idea that intergroup competition serves distinct functionality in selecting for cooperative traits (Burton-Chellew et al. 2010; Bowles 2009) and, perhaps, intelligence. As stated by Alexander: “...the real challenge in the human environment throughout history ... was the necessity of dealing continually with our fellow humans in social circumstances that became ever more complex and unpredictable as the human line evolved. ... nothing would select more potently for increased social intelligence ... than a within-species co-evolutionary arms race in which success depended on effectiveness in social competition" (1990, pp. 4-7). Indeed, intergroup competition motivates individuals to overcome within-group rivalry and to cooperatively share information even-handedly, ultimately helping them to make smart decisions.

Acknowledgements Financial support was provided by the Netherlands Science Foundation (Grant NWO-432-08-002 and NWO SPI-57-242). CKWDD, TDW and FSTV conceived of the project, designed the experiments, analyzed the data and discussed analyses and results. TDW and FSTV coordinated data collection. CKWDD wrote the paper and incorporated co-author revisions. We thank Nadira Faber and two anonymous reviewers for constructive feedback on an earlier version of this paper.

\section{Declarations}

Conflict of interest The authors declare that they have no conflict of interest. 
Open Access This article is licensed under a Creative Commons Attribution 4.0 International License, which permits use, sharing, adaptation, distribution and reproduction in any medium or format, as long as you give appropriate credit to the original author(s) and the source, provide a link to the Creative Commons licence, and indicate if changes were made. The images or other third party material in this article are included in the article's Creative Commons licence, unless indicated otherwise in a credit line to the material. If material is not included in the article's Creative Commons licence and your intended use is not permitted by statutory regulation or exceeds the permitted use, you will need to obtain permission directly from the copyright holder. To view a copy of this licence, visit http://creativecommons.org/licen ses/by/4.0/.

\section{References}

Akinola M, Page-Gould E, Mehta PH, Lu JG (2016) Collective hormonal profiles predict group performance. Proc Natl Acad Sci 113:9774-9779

Aldag R, Fuller SR (1993) Beyond fiasco: a reappraisal of the groupthink phenomenon and a new model of group decision processes. Psychol Bull 113:535-552

Alexander RD (1990) How did humans evolve? Reflections on the uniquely unique species. Museum of Zoology (Special Publication No. 1). The University of Michigan, Ann Arbor

Bahrami B, Olson K, Latham PE, Roepstorff A, Rees G, Frith CD (2010) Optimally interacting minds. Science 329:1081-1085

Balliet D, Wu Y, De Dreu CKW (2014) In-group favoritism and cooperation: a meta-analysis. Psychol Bull 140:1556-1581

Bernhard H, Fischbacher U, Fehr E (2006) Parochial altruism in humans. Nature 442:912-915

Böhm R, Rockenbach B (2013) The inter-group comparison-intra-group cooperation hypothesis: comparisons between groups increase efficiency in public goods provision. PLoS ONE

Bond R, Smith PB (1996) Culture and conformity: a meta-analysis of studies using Asch's (1952b, 1956) line judgment task. Psychol Bull 119:111-137

Bonner BL, Soderberg AT, Romney AC (2016) In the same group but moving in different directions: coordination effects in tasks with simultaneous intellective and judgmental performance criteria. $\mathrm{J}$ Exp Psychol Appl 22:471-487

Bornstein G (2003) Intergroup conflict: Individual, group, and collective interests. Pers Soc Psychol Rev 7:129-145

Bowles S (2009) Did warfare among ancestral hunter-gatherers affect the evolution of human social behaviors? Science 324:1293-1298

Bowman JM, Wittenbaum GM (2012) Time pressure affects process and performance in Hidden-Profile Groups. Small Group Research 43:295-314

Brodbeck FC, Kerschreiter R, Mojzisch A, Schulz-Hardt S (2007) Group decision making under conditions of distributed knowledge: The information asymmetries model. Acad Manag Rev 32:459-479

Burton-Chellew MN, Ross-Gillespie A, West SA (2010) Cooperation in humans: competition between groups and proximate emotions. Evol Hum Behav 31:104-108

Chen CX, Williamson MG, Zhou FH (2012) Reward system design and group creativity: An experimental investigation. Accounting Review 87:1885-1911

Dayeh V, Morrison BW (2020) The effect of perceived competence and competitive environment on team decision-making in the hidden-profile paradigm. Group Decis Negot 29:1181-1205

De Dreu CKW (2007) Cooperative outcome interdependence, task reflexivity, and team effectiveness: a motivated information processing perspective. J Appl Psychol 92:628-638

De Dreu CKW, Gross J (2019) Revisiting the form and function of conflict: neurobiological, psychological and cultural mechanisms for attack and defense within and between groups. Behav Brain Sci 42:1-44

De Dreu CKW, Van Knippenberg D (2005) The possessive self as a barrier to constructive conflict management: Effects of mere ownership, process accountability, and self-concept clarity on competitive cognitions and behavior. J Pers Soc Psychol 89:345-357

De Dreu CKW, Weingart LR, Kwon S (2000) Influence of social motives on integrative negotiation: a meta-analytical review and test of two theories. J Pers Soc Psychol 78:889-905 
De Dreu CKW, Nijstad BA, van Knippenberg D (2008) Motivated information processing in group judgment and decision making. Pers Soc Psychol Rev 12:22-49

De Dreu CKW, Gross JAJ, Meder Z, Griffin MR, Prochazkova E, Krikeb J, Columbus S (2016) In-group defense, out-group aggression, and coordination failure in intergroup conflict. Proc Nat Acad Sci 113:10524-10529

De Dreu CKW, Gross J, Farina A, Ma Y (2020) Group cooperation, carrying-capacity stress, and intergroup conflict. Trends Cogn Sci 24:760-776

De Wilde TRW, Ten Velden FS, De Dreu CKW (2017) The neuropeptide oxytocin enhances information sharing and group decision making quality. Nat Sci Rep 7:40622

De Wilde TRW, Ten Velden FS, De Dreu CKW (2018) The anchoring-bias in groups. J Exp Soc Psychol 76:116-126

Esser JK, Lindoerfer JL (1989) Groupthink and the space shuttle Challenger accident: toward a quantitative analysis. J Behav Decis Mak 2:167-177

Faber NS, Hausser JA, Kerr NL (2017) Sleep deprivation impairs and caffeine enhances my performance but not always our performance: how acting in a group can change the effects of impairments and enhancements. Pers Soc Psychol Rev 21:3-28

Faulmüller N, Kerschreiter R, Mojzisch A, Schulz-Hardt S (2010) Beyond group-level explanations for the failure of groups to solve hidden profiles: the individual preference effect revisited. Group Process Intergroup Relat 13:653-671

Faulmüller N, Mojzisch A, Kerschreiter R, Schulz-Hardt S (2012) Do you want to convince me or to be understood? Preference-consistent information sharing and its motivational determinants. Pers Soc Psychol Bull 38:1684-1696

Gigone D, Hastie R (1993) The common knowledge effect: information sharing and group judgment. J Pers Soc Psychol 65:959-974

Greitemeyer T, Schulz-Hardt S (2003) Preference-consistent evaluation of information in the hidden profile paradigm: Beyond group-level explanations for the dominance of shared information in group decisions. J Pers Soc Psychol 84:322-339

Harinck F, De Dreu CKW, Van Vianen AEM (2000) The impact of conflict issues on fixed-pie perceptions, problem solving, and integrative outcomes in negotiation. Organ Behav Hum Decis Process 81:329-358

Hart W, Albarracin D, Eagly AH, Brechan I, Lindberg MJ, Merrill L (2009) Feeling validated versus being correct: a meta-analysis of selective exposure to information. Psychol Bull 135:555-588

Hayes AF (2013) Introduction to mediation, moderation, and conditional process analysis: a regression-based approach. Guilford Press, New York

Henrich J, Boyd R (1998) The evolution of conformist transmission and the emergence of betweengroup differences. Evol Hum Behav 19:215-241

Janis IL, Mann L (1977) Decision making: a psychological analysis of conflict, choice and commitment. Free Press, New York

Kelly JR, Loving TJ (2004) Time pressure and group performance: exploring underlying processes in the Attention Focus Model. J Exp Soc Psychol 40:185-198

Kerr NL, Tindale RS (2004) Group performance and decision making. Annu Rev Psychol 55:623-655

Kerr NL, MacCoun RJ, Kramer GP (1998) Bias in judgment comparing individuals and groups. Psychol Rev 103:687-719

Kolb MR, Van Swol LM (2018) Manipulating a synchronous or seperatist group orientation to improve performance on a hidden profile task. Group Process Intergroup Relat 21:57-72

Kruglanski AW, Pierro A, Mannetti L, De Grada E (2006) Groups as epistemic providers: need for closure and the unfolding of group centrism. Psychol Rev 113:84-100

Laughlin PR, Hatch EC, Silver JS, Bohn L (2006) Groups perform better than the best individuals on letters-to-numbers problems: Effects of group size. J Pers Soc Psychol 90:644-651

Lopez AC (2020) Making 'my' problem 'our' problem: Warfare as collective action, and the role of leader manipulation. Leadersh Quart 31:101294

Lu L, Yuan YC, McLeod PL (2012) Twenty-five years of hidden profiles in group decision making: a meta-analysis. Pers Soc Psychol Rev 16:54-75

Mesmer-Magnus JR, DeChurch LA (2009) Information sharing and team performance: a meta-analysis. J Appl Psychol 94:535-546

Mojzisch A, Schulz-Hardt S, Kerschreiter R, Brodbeck FC, Frey D (2008) Social validation in group decision-making: differential effects on the decisional impact of preference-consistent and preference-inconsistent information. J Exp Soc Psychol 44:1477-1490 
Nevicka B, Ten Velden FS, De Hoogh AHB, Van Vianen AEM (2011) Reality at odds with perceptions: narcissistic leaders and group performance. Psychol Sci 22:1259-1264

Nijstad BA, De Dreu CKW (2012) Motivated information processing in groups: progress, puzzles, and prospects. Res Organ Behavr 32:87-111

Scholten L, Van Knippenberg D, Nijstad BA, De Dreu CKW (2007) Motivated information processing and group decision making: effects of process accountability and information dissemination. J Exp Soc Psychol 43:539-552

Schulz-Hardt S, Mojzisch A (2012) How to achieve synergy in group decision making: Lessons to be learned from the hidden profile paradigm. Eur Rev Soc Psychol 23:305-343

Stangor C, McMillan D (1992) Memory for expectancycongruent and expectancy-incongruent information: a review of the social and social developmental literatures. Psychol Bull 111:42-61

Stasser G, Titus W (1985) Pooling of unshared information in group decision making: biased information sampling during discussion. J Pers Soc Psychol 48:1467-1478

Stasser G, Vaughan SI, Stewart DD (2000) Pooling unshared information: the benefits of knowing how access to information is distributed among group members. Organ Behav Hum Decis Process 82:102-116

Steinel W, Utz S, Koning L (2010) The good, the bad and the ugly thing to do when sharing information: revealing, concealing and lying depend on social motivation, distribution and importance of information. Organ Behav Hum Decis Process 113:85-96

Tetlock PE, Peterson RS, McGuire C, Chang SJ, Feld P (1992) Assessing political group-dynamics: a test of the groupthink model. J Pers Soc Psychol 63:403-425

Toma C, Butera F (2009) Hidden profiles and concealed information: strategic information sharing and use in group decision making. Pers Soc Psychol Bull 35:793-806

Toma C, Gilles I, Butera F (2013) Strategic use of preference confirmation in group decision making: the role of competition and dissent. Br J Soc Psychol 52:44-63

van Bunderen L, Greer L, van Knippenberg D (2018) When interteam conflict spirals into intrateam power struggles: the pivotal role of team power structures. Acad Manag J 61:1100-1130

Van Ginkel WP, Van Knippenberg D (2012) Group leadership and shared task representations in decision making groups. Leadership Q 23:94-106

Van Dijk E, De Dreu CKW (2021) Experimental games and social decision-making. Ann Rev Psychol 72:2021

Wittchen M, van Dick R, Hertel G (2011) Motivated information processing during intergroup competition: a model of intergroup competition effects on individual effort. Organ Psychol Rev 1:257-272

Wittenbaum GM, Hubbell AP, Zuckerman C (1999) Mutual enhancement: toward an understanding of collective preferences for shared information. J Pers Soc Psychol 77:967-978

Wittenbaum GM, Hollingshead AB, Botero IC (2004) From cooperative to motivated information sharing in groups: moving beyond the hidden profile paradigm. Commun Monogr 71:286-310

Yang J, Zhang H, Ni J, De Dreu CKW, Ma Y (2020) Within-group neural synchronization in the prefrontal cortex associates with intergroup conflict. Nat Neurosci 23:754-760

Zhao ZJ, Chen HH, Li KW (2020) Management of interpersonal conflict in negotiation with Chinese: a perceived face threat perspective. Group Decis Negot 29:75-102

Publisher's Note Springer Nature remains neutral with regard to jurisdictional claims in published maps and institutional affiliations. 